\title{
The effects of standing tutorials on learning in undergraduate students: Study protocol
}

Citation for published version (APA):

Chim, HQ., van Gerven, P. W. M., de Groot, R., Oude Egbrink, M., Erkens, R., \& Savelberg, H. (2019). The effects of standing tutorials on learning in undergraduate students: Study protocol. International Journal of Educational Research, 98, 123-133. https://doi.org/10.1016/j.ijer.2019.08.005

Document status and date:

Published: 01/01/2019

DOI:

10.1016/j.jjer.2019.08.005

Document Version:

Publisher's PDF, also known as Version of record

Document license:

Taverne

Please check the document version of this publication:

- A submitted manuscript is the version of the article upon submission and before peer-review. There can be important differences between the submitted version and the official published version of record.

People interested in the research are advised to contact the author for the final version of the publication, or visit the DOI to the publisher's website.

- The final author version and the galley proof are versions of the publication after peer review.

- The final published version features the final layout of the paper including the volume, issue and page numbers.

Link to publication

\footnotetext{
General rights rights.

- You may freely distribute the URL identifying the publication in the public portal. please follow below link for the End User Agreement:

www.umlib.nl/taverne-license

Take down policy

If you believe that this document breaches copyright please contact us at:

repository@maastrichtuniversity.nl

providing details and we will investigate your claim.
}

Copyright and moral rights for the publications made accessible in the public portal are retained by the authors and/or other copyright owners and it is a condition of accessing publications that users recognise and abide by the legal requirements associated with these

- Users may download and print one copy of any publication from the public portal for the purpose of private study or research.

- You may not further distribute the material or use it for any profit-making activity or commercial gain

If the publication is distributed under the terms of Article $25 \mathrm{fa}$ of the Dutch Copyright Act, indicated by the "Taverne" license above, 


\title{
The effects of standing tutorials on learning in undergraduate students: Study protocol
}

\author{
H.Q. Chim ${ }^{\mathrm{a}, *}$, Pascal W.M. Van Gerven ${ }^{\mathrm{b}}$, Renate H.M. de Groot ${ }^{\mathrm{c}, \mathrm{d}}$, \\ Mirjam G.A. oude Egbrink ${ }^{\mathrm{e}}$, Roy H.J. Erkens ${ }^{\mathrm{f}}$, Hans H.C.M. Savelberg ${ }^{\mathrm{a}}$ \\ ${ }^{a}$ Department of Nutrition and Movement Sciences, School of Health Professions Education (SHE), Faculty of Health, Medicine and Life Sciences, \\ Maastricht University, 6200 MD, Maastricht, the Netherlands \\ ${ }^{\mathrm{b}}$ Department of Educational Development and Research, School of Health Professions Education (SHE), Faculty of Health, Medicine and Life Sciences, \\ Maastricht University, 6200 MD, Maastricht, the Netherlands \\ ${ }^{\mathrm{c}}$ Welten Institute - Research Centre for Learning, Teaching and Technologies, Faculty of Psychology and Educational Sciences, Open University of the \\ Netherlands, 6419AT Heerlen, the Netherlands \\ ${ }^{\mathrm{d}}$ Department of Complex Genetics, School of Nutrition and Translational Research in Metabolism, the Netherlands \\ e Department of Physiology, School of Health Professions Education (SHE), Faculty of Health, Medicine and Life Sciences, Maastricht University, 6200 \\ MD, Maastricht, the Netherlands \\ ${ }^{\mathrm{f}}$ Maastricht Science Programme, Faculty of Science and Engineering, Maastricht University, $6200 \mathrm{MD}$, Maastricht, the Netherlands
}

\section{A R T I C L E I N F O}

\section{Keywords:}

Higher education

Physical activity monitoring

Problem-based learning

Sedentary behavior

Academic achievement

Mixed-methods

\begin{abstract}
A B S T R A C T
Standing classrooms could potentially counteract excessive sedentary behavior. This paper describes the protocol for an exploratory longitudinal randomized controlled trial aimed at studying the effects of standing during tutorials on learning in undergraduate students. Learning is operationally defined as the use of interactions that are conducive to learning and an improved performance on concept tests. Final examination scores are also used as a measure of learning performance. The secondary aim is to explore the unintended effects of standing tutorials through the students' subsequent physical activity, tutorial attendance, and affect. Participants were randomly recruited to a sitting or standing tutorial for nine weeks. This study addresses learning in a real-world setting and reveals insights on the effects of standing on learning.
\end{abstract}

\section{Introduction}

Sedentary behavior (SB) is an umbrella term for all activities that are carried out while being awake in a sitting, reclining or lying posture, and expending energy at 1.5 metabolic equivalents (METs) or less (Tremblay et al., 2017). Excessive SB has been associated with increased health risks, e.g., weight gain (Ball, Brown, \& Crawford, 2002; Brown, Williams, Ford, Ball, \& Dobson, 2005; Coakley, Rimm, Colditz, Kawachi, \& Willett, 1998; Mekary et al., 2009; Oken, Taveras, Popoola, Rich-Edwards, \& Gillman, 2007; Raynor, Phelan, Hill, \& Wing, 2006), obesity (Boone, Gordon-Larsen, Adair, \& Popkin, 2007; Ching et al., 1996; Hu, Li, Colditz, Willett, \& Manson, 2003; Landhuis, Poulton, Welch, \& Hancox, 2008; Meyer et al., 2008), cardiovascular diseases (Manson et al., 2002), mental

\footnotetext{
Abbreviations: BMS, biomedical sciences; CONSORT, consolidated standards for reporting trials; H, hypothesis; IPAQ, international physical activity questionnaire; LIWC2015, linguistic inquiry and word count 2015; METs, metabolic equivalents; NVMO, Netherlands Association for Medical Education; NERB, NVMO Ethical Review Board; PANAS, positive and negative affect schedule; PBL, problem-based learning; RCT, randomized, controlled trials; SB, sedentary behavior; SRQR, standards for reporting qualitative research

* Corresponding author at: P.O.Box 616, 6200MD Maastricht, the Netherlands.

E-mail address: hq.chim@maastrichtuniversity.nl (H.Q. Chim).
} 
disorders (Sanchez-Villegas et al., 2008) and mortality (Dunstan et al., 2010; Katzmarzyk, Church, Craig, \& Bouchard, 2009; Patel et al., 2010; Stamatakis, Hamer, \& Dunstan, 2011; Warren et al., 2010; Wijndaele et al., 2011). With the general population spending at least $54.9 \%$ of their waking time (or 7.7 hours a day) being sedentary (Matthews et al., 2008), various governmental bodies across the globe have called for action to reduce SB (Aragonés et al. (2015); Australian Government - Department of Health, 2014; Bundesamt für Sport BASPO, 2013; Department of Health, 2011; Flemish Institute for Health Promotion \& Disease Prevention, 2015; Health Promotion Board, 2011; Ministry of Health, 2015; Nordic Council of Ministers, 2012; Ruetten \& Pfeifer, 2016; Titze et al., 2012; World Health Organization \& Regional Office for the Western Pacific, 2018). To counteract the prevalence of SB, standing desks have been suggested and implemented within classrooms (Minges et al., 2016).

Through reviewing current literature on standing classrooms, Hinckson et al. (2015) found that standing desks do effectively reduce SB of students. However, the authors warn that there is still inadequate research on the influence of these interventions on learning or cognitive functioning. The main concern for standing is that postural control is attentionally demanding. For example, both Lajoie, Teasdale, Bard, and Fleury, (1993)) and Vuillerme, Isableu, and Nougier, (2006)) found that young adults had slower reaction times when standing, compared to when they were sitting. However, a longitudinal intervention by Mehta and colleagues (2016) showed both positive and neutral influences of standing on cognitive functioning. In their study, high school students who used standing desks showed improvements on standardized tests of executive functions such as the Wisconsin Card Sorting Test and Stroop Test, although there were no significant changes in their performance of the Flanker Test, Memory Span, and Trail Making Test (Mehta, Shortz, \& Benden, 2016). In a meta-analytical study, Chang, Labban, Gapin, and Etnier, (2012)) found that moderators such as exercise duration, exercise intensity, participant fitness levels and the type of cognitive assessment significantly affected the exercise-cognition relationship, which could potentially explain the variety of results present in extant literature. Therefore, when exploring the effects of introducing standing classrooms, the predetermined factors of real-life educational settings (e.g., the duration that students are expected to stand in their classes and the type of learning specific to the educational model used) have to be given explicit attention.

At Maastricht University, a typical tutorial class lasts for two hours and accommodates small groups of 12 students (Maastricht University). Students learn through problem-based learning (PBL), an educational model utilized by the university (Bouhuijs \& Gijselaers, 1993; Hmelo-Silver, 2004; Maastricht University (2019)). With PBL, students are guided by a tutor while they solve academically or professionally relevant problems as a group. PBL typically starts with a pre-discussion phase, in which students are presented with a problem. Within their group discussions, the students share their prior knowledge of the problem, brainstorm around what they know and do not know, and identify learning goals. The students then disperse to study independently based on the learning goals. When they reconvene in their next tutorial, they share and discuss their findings during the post-discussion phase. In a study by Knight and Baer (2014), standing meetings led to increased information elaboration and improved group performance. The authors explained that non-sedentary workspaces increase arousal levels and decrease territoriality of ideas, leading to improved discussions (see Fig. 1). With student discussions being the core of PBL, improved discussions should theoretically lead to improved PBL (see Fig. 2).

The current paper describes a protocol for an exploratory longitudinal randomized controlled trial (RCT). The aim of this study is to explore the effects of standing tutorial classes on learning in undergraduate students at Maastricht University. Due to the multifaceted nature of learning, a mixed-methods approach was used to measure learning within this study. Learning is operationally defined as the students' use of interactions that are conducive to learning in their tutorial discussions and an improved performance on the concept tests. The final examination on the course will also be used as a measure of learning performance. It is hypothesized that standing tutorials will result in more student discussions that are conducive to learning (H1), leading to improved learning of academic concepts (H2), and resulting in better exam grades (H3) compared to sitting tutorials. The secondary aim of this study is to explore unintended effects of standing tutorials through the students' subsequent physical activity levels, tutorial attendance, and positive and negative affect. The introduction of standing tutorials is hypothesized to be a feasible solution in that it counteracts excessive SB, without influencing the students' subsequent physical activity, attendance and affect (H4).

\section{Methods}

\subsection{Participants}

According to the Special Eurobarometer 412 report, populations reporting the highest sitting time within the European Union

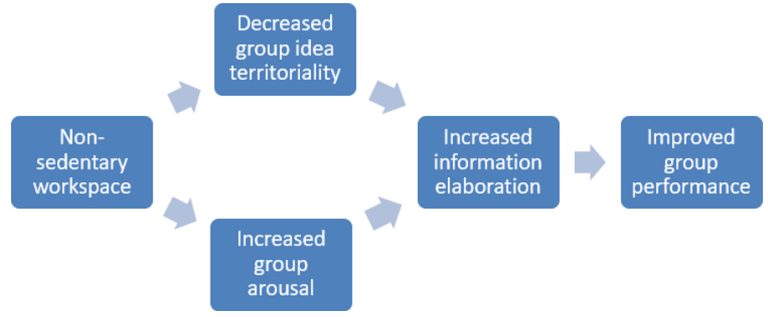

Fig. 1. Path analysis on the effects of non-sedentary workspace (Knight \& Baer, 2014). 


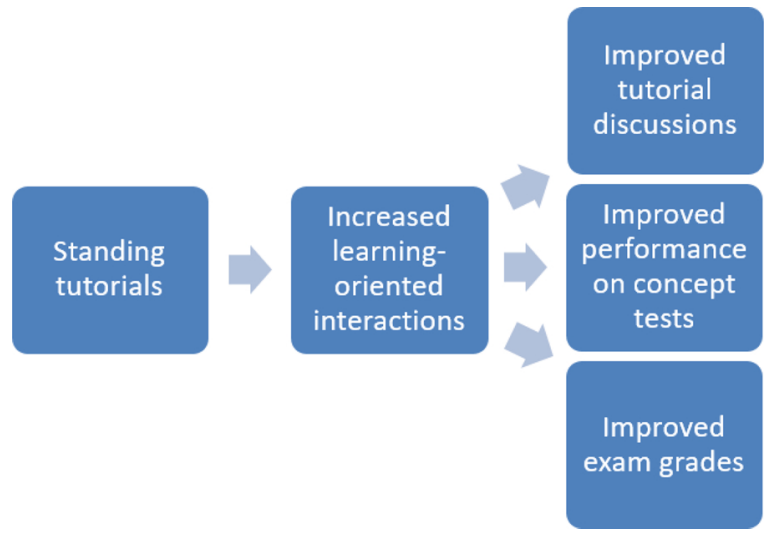

Fig. 2. Logic model built upon Knight and Baer (2014) results.

include, but are not limited to students, those aged between 18 and 24 years, and those from the Netherlands and Denmark (Loyen, van der Ploeg, Bauman, Brug, \& Lakerveld, 2016). Considering that the adolescent brain - specifically the prefrontal cortex which is essential for learning (Fuster, 2002) - only accomplishes maturation around the age of 25 (Arain et al., 2013), the target population for this exploratory RCT was Maastricht University's students with an age range of 18-25. As the measurement of learning needs to be tailored to a specific PBL course, first-year Biomedical Sciences (BMS) bachelor students of Maastricht University were invited to take part in this exploratory RCT. An announcement containing the details of the study was posted through the BMS online student portal to invite interested students to participate voluntarily in this exploratory RCT.

An a-priori power analysis indicated that a minimal sample size of 56 total participants is required to compare the main quantitative outcome (i.e., concept test performance across time) between sitting and standing tutorials ( $\alpha=.05$, Cohen's $f=.2$,'statistical power of 0.95, G*Power: Statistical Power Analyses for Windows, version 3.1.9.2; (Faul, Erdfelder, Lang, \& Buchner, 2007). In total, 135 students expressed their interest to participate in this exploratory RCT. Each tutorial classroom at Maastricht University is able to accommodate 12 students, i.e., a typical PBL classroom size. Furthermore, a typical tutorial within the BMS course was scheduled at either 8:30 or 11:00 in the morning. Therefore, the final sample size required multiples of 48 (12 students * 2 conditions (sit or stand) * 2 schedules). The faculty's administrative coordinator randomly recruited and randomly allocated 96 students (resulting in 36 male and 60 female students) from the pool of interested students to a sitting or standing tutorial, with both conditions equally distributed across the earlier and later schedules.

\subsection{Design}

This study received ethical approval by the Netherlands Association for Medical Education (NVMO), with NVMO Ethical Review Board (NERB) dossier number: 1030. This study is registered with Clinical Trials, with identifier number: NCT03493659.

This exploratory RCT has a longitudinal, field experimental design. Of the eight participating tutorial groups, four were Standing Groups, i.e., the students stood during the tutorial sessions. The other four were Sitting Groups, i.e., the students sat down in a traditional tutorial setting. Both Standing and Sitting Groups maintained their natural standing or sitting posture throughout the 2 -h tutorial sessions, twice a week, across the 9-week course. Two Standing Groups and two Sitting Groups took place from 8:30-10:30, while the remaining groups took place later at 11:00-13:00. All tutorial sessions were scheduled on Tuesdays and Fridays, and were part of the Human Genetics, Reproduction and Prenatal Development course that lasted across April 2018-June 2018.

A repeated-measures, mixed-method design was used to study the effects of standing tutorials on the multifaceted concept of learning. Learning was measured through the students' final exam grades on the course, the quality of tutorial discussions and the administration of concept tests (see section 2.4 Measures and Materials). Method triangulation was used to raise the validity of the learning measure.

Concept tests and various questionnaires were administered after the regular tutorial sessions. As shown in Table 1, Standing

Table 1

Stand/Sit Allocation of Tutorial Groups.

\begin{tabular}{|c|c|c|c|c|}
\hline $8: 30-10: 30$ & $\underline{\text { Standing Group } 1}$ & $\underline{\text { Standing Group } 2}$ & Sitting Group 3 & Sitting Group 4 \\
\hline Regular tutorial: & Stand & Stand & Sit & Sit \\
\hline Concept Tests \& Questionnaires: & Stand & Sit & Sit & Stand \\
\hline 11:00-13:00 & $\underline{\text { Standing Group } 5}$ & $\underline{\text { Standing Group } 6}$ & Sitting Group 7 & $\underline{\text { Sitting Group } 8}$ \\
\hline Regular tutorial: & Stand & Stand & Sit & Sit \\
\hline Concept Tests \& Questionnaires: & Stand & Sit & Sit & Stand \\
\hline
\end{tabular}


Groups 2 and 6 were instructed to sit down when answering the concept tests and questionnaires. For Sitting Groups 4 and 8 , the students were instructed to stand up for the concept tests and questionnaires. This postural change aimed to test potential carry-over and/or acute effects of standing.

\subsection{Classroom setting}

The tutorial classrooms were equipped with five electronic desks, which accommodated for 12 students. Each desk had a dimension of $160 \times 80 \mathrm{~cm}$ with an adjustable height ranging from 70 to $130 \mathrm{~cm}$. Prior to the start of each tutorial, the desks used in the Sitting Group were adjusted to a height of $70 \mathrm{~cm}$, and those in the Standing Group to a height of $110 \mathrm{~cm}$. Nevertheless, students were informed and constantly reminded to adjust the height of the desks so that they were at an ergonomically comfortable height for their posture, i.e., with elbows approximately at a 90-degree angle (see Figs. 1 and 2). The desks were arranged such that all students could face each other, to stimulate face-to-face discussions.

The four classrooms were situated adjacent to each other. Each classroom was equipped with a computer, a projector, a screen, a notice board, and a whiteboard with markers. The classroom setting was standardized with the exception of the chairs: when students were not using the chairs in standing tutorials, the chairs were pushed underneath the standing desks (see Figs. 3 and 4).

\subsection{Measures and materials}

\subsubsection{Learning: tutorial discussions, concept tests \& exam grades}

Learning was measured around two pre-defined and well-established PBL topics within the course: (1) Early embryonic development until blastocyst, and gene regulation and (2) Limb development and apoptosis in development. As discussions are an integral part of the PBL process, the pre- and post-discussions of these two topics were recorded with a Philips DVT6010 audio recorder. The researcher was not present during the audio recording to encourage a natural tutorial setting.

In a meta-analysis by Gijbels, Dochy, Van den Bossche, and Segers, (2005)), the authors posit that a valid assessment of learning in PBL has to measure both the understanding of academic concepts and how these concepts are linked to one another. Therefore, concept tests comprising of free recall and concept mapping were administered to the students. Free recall was used to measure the students' learning of singular concepts, and concept mapping was used to measure how well the students were able to link the singular concepts.

The measurements took place around the PBL structure as described in section 1. Introduction. As shown in Fig. 5, one week prior to the pre-discussion phases of both PBL topics, a pre-test concept test was administered to the students to measure their prior knowledge of the PBL topics. The one-week washout period was intended to minimize any testing effects that may influence the learning during the actual tutorials. Next, three post-test concept tests were administered to measure the students' learning of the PBL topics. The first post-test was administered after the pre-discussion phase. The second post-test was administered after the postdiscussion phase. The third post-test was administered two weeks after the post-discussion phase to measure how much of the

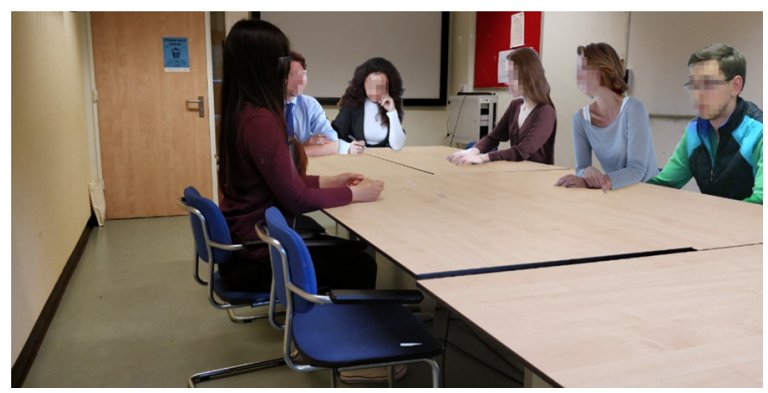

Fig. 3. Example of a Sitting Tutorial Classroom.

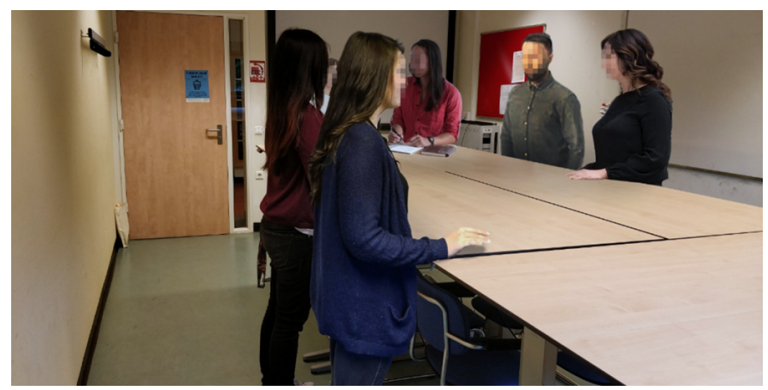

Fig. 4. Example of a Standing Tutorial Classroom. 


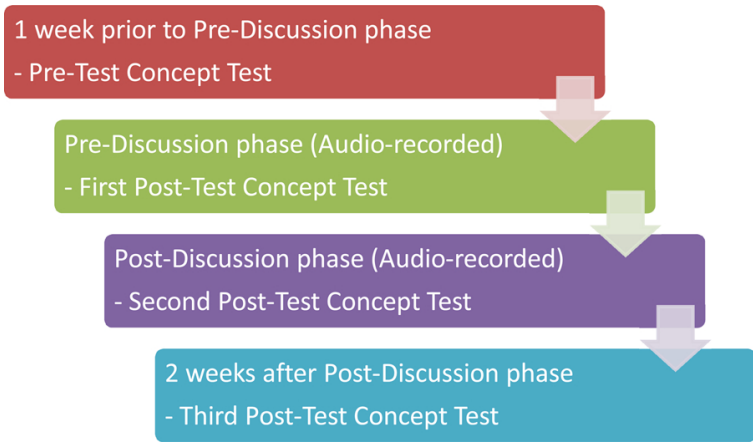

Fig. 5. Administration of Concept Tests and Audio-Recording.

students' learning was retained.

Furthermore, the students' anonymized exam grades of the course were acquired after their final examination through the Board of Examiners. The exam grades will be used to compare between the sitting and standing tutorial groups.

\subsubsection{Exploration of unintended effects: subsequent activity levels, attendance \& affect}

2.4.2.1. Subsequent activity levels. As the current study introduced a physical activity intervention, the students' subsequent activity levels were measured in the fourth and eighth week to capture any changes in activity levels that resulted from the intervention. To obtain a complete measurement of both physical activity and SB (Atkin et al., 2012), the activPAL triaxial physical activity logger was attached to the middle-anterior of the students' thigh (PAL Technologies Ltd. et al., 2010). During the first measurement, the activPAL was attached on the students' right thigh. During the second measurement, the left thigh was used to avoid the unlikely risk of irritating the skin of the right thigh. In their pilot study, Van Dijk, De Groot, Savelberg, Van Acker, and Kirschner, (2014)) found no recording differences between using the right and left thigh for the activPAL measurement. Each time, the students were asked to wear the activPAL for seven continuous days to measure their activity levels across the week (Edwardson et al., 2017). The activPALs were waterproofed by inserting the devices into a nitrile sleeve and wrapping them with a medical grade adhesive dressing, i.e., the $3 \mathrm{M}^{\mathrm{TM}}$ Tegaderm ${ }^{\mathrm{TM}}$ transparent film, to make continuous wear possible.

The students were given sufficient attachment materials to allow them to change the dressings if needed. Six pieces of $10 \times 10 \mathrm{~cm}$ $3 \mathrm{M}^{\mathrm{TM}}$ Tegaderm ${ }^{\mathrm{TM}}$ films were provided for attachment. Six compression bandages $(5 \times 5 \mathrm{~cm})$ were provided to place between the activPAL and the skin, as the compression bandages provide a gentler contact to the skin.

To minimize the effects of extraneous variables, all students were instructed to attach the activPAL on the day of receiving the activPAL package. All the activPALs were programmed to start measuring activity at the stroke of midnight post-attachment. Two steps were taken to accommodate for the large sample size: First, the students were given both written and video instructions alongside the activPAL and attachment materials, to attach the activPAL accelerometer on their own at home. Kringen, Healy, Winkler, and Clark, (2016)) found that students were able to self-attach their activPALs with acceptable accuracy under such instructions. Secondly, two models of activPALs were used - the activPAL3 ${ }^{\mathrm{TM}}$ with $35 \times 53 \times 7 \mathrm{~mm}$, weighing $15 \mathrm{~g}$ (PAL Technologies Ltd, 2010) and the activPAL3 ${ }^{\mathrm{TM}}$ micro, which is $40 \%$ smaller, weighing $9 \mathrm{~g}$ (Pal Technologies Ltd, 2018). Using the Intelligent Activity Classification $^{\mathrm{TM}}$, both activPAL models objectively measure sit-to-stand transitions, step counts, and the time spent sedentary, standing and walking.

Furthermore, when wearing the activPAL accelerometer, the students were instructed to complete a daily diary, designed based on the International Physical Activity Questionnaire (IPAQ; Craig et al., 2003). The students were instructed to complete the questionnaire as close to bedtime as possible. The daily diary served as a supplementary check for wear compliance of the activPAL.

2.4.2.2. Attendance. Throughout the nine-week course, there were 13 tutorial sessions in total. With the permission of the students, the attendance lists were obtained from the tutors at the end of the course. The reason for this is twofold: first, to check whether there is a difference in attendance rate because of the intervention; second, to check whether the tutorial group discussions were affected by the level of attendance.

2.4.2.3. Modified positive and negative affect schedule (PANAS) questionnaire. The modified PANAS questionnaire is a reliable and valid instrument consisting of 10 items to measure positive affect and 10 items to measure negative affect (Watson, Clark, \& Tellegen, 1988). This questionnaire was administered at the end of the course to assess the students' feelings across the course. The students were asked to self-report each item on a 5-point scale, ranging from 1 (not at all) to 5 (very much). In terms of positive affect, a high score indicates high levels of energy, concentration and pleasant engagement, while a low score suggests that one feels sad and lethargic. For negative affect, high scores point to distress and unpleasant engagement, whereas low scores point to feelings of calmness and serenity. Instead of asking the students how they "feel on the average" (as in the original questionnaire), this study asked them how they "feel throughout the tutorial course". 


\subsubsection{Further questionnaires}

Due to the exploratory nature of this study, further questionnaires were administered in order to study potential confounding variables:

1 Questionnaire for Search, Preparing and Reporting Phase: This questionnaire was given to students after the audio-recorded postdiscussions to measure the extent of the students' individual study and their perceptions of the post-discussions (van den Hurk, Dolmans, Wolfhagen, Muijtjens, \& van der Vleuten, 1999). The questionnaire consists of five factors with reasonable construct (van den Hurk et al., 1999). The five factors span across 23 items with a five-point Likert scale, ranging from 1 (totally disagree) to 5 (totally agree):

- five items on the learning issue driven searching - high scores suggest that the students had used the learning goals when seeking out literature to study from

- four items on extensiveness of searching - high scores suggest that the students had sought and compared a high number of resources from various literature sources

- six items on the explanation-oriented preparing phase - high scores suggest that the students studied in a manner that is conducive for their subsequent discussions

- four items on the breadth of the discussion (upon reconvening) - high scores suggest that the discussion consists of various findings from various resources

- four items on the depth of the discussion (upon reconvening) - high scores suggest a high application and integration of the newly learned information during the discussion

2 Learning-oriented Interactions Questionnaire: The tutors were asked to complete this validated questionnaire (Visschers-Pleijers, Dolmans, Wolfhagen, \& van der Vleuten, 2005) after the audio-recorded pre- and post-discussions to measure their perception on the quality of the discussions. The questionnaire consists of 11 items on a five-point Likert scale, ranging from 1 (completely disagree) to 5 (completely agree): four items cover exploratory questions; four items cover cumulative reasoning; and three items cover handling conflicts about knowledge. These three learning-oriented interaction themes are described in detail under the 2.7 Analysis section.

3 Tutor Evaluation Questionnaire: The students were asked to evaluate their tutor at the end of the course with a short Tutor Evaluation Questionnaire, loosely based on a validated questionnaire by Dolmans and Ginns (2005). This questionnaire was part of the course, and not specifically designed for this study. With the permission of the students and tutors, the results of this evaluation were obtained from the university's department of Educational Development and Research. The questionnaire consisted of seven questions with a five-point Likert scale, ranging from 1 (strongly disagree) to 5 (strongly agree). The seven questions include questions on the productivity of the tutorial group, the overall performance of the tutor, the quality of the tutor's feedback, and the extent to which the tutor stimulated cumulative, self-directed, contextual, and collaborative learning. The higher the score, the better the tutor performance, problem-solving performance, and/or group productivity.

\subsection{Procedure}

Five volunteer research assistants were given training on the procedure prior to the start of this study. These five research assistants were given written material and practical training (including mock presentations) to guide the students through the study. Although there were only four tutorials running at each point in time, five research assistants were trained to prepare for unforeseen circumstances (e.g., illness).

On February 5, 2018, two months prior to the start of this study, all tutors in the course were sent an e-mail containing the details of the study and details on how to sign up for the study. Four tutors were recruited to each lead two of the tutorial groups included in the current study. The tutorial allocation was randomized and counterbalanced so that each tutor led one Sitting Group and one Standing Group, and all four tutors were involved in one early morning and one late morning tutorial session. The tutors continued tutoring the same assigned groups throughout the course. Prior to the start of the course, each tutor was briefed in detail and asked to sign their informed consent. Due to the study being part of a real educational schedule, no parties were blinded.

Prior to the start of the study, the 96 students were given detailed information through their e-mail accounts. A face-to-face briefing was carried out at the start of the study. The students were given the opportunity to ask questions at any time during the study. Concerning the participation of this study, written and verbal consent were obtained from each participant. The students were reminded that their involvement in this study is voluntary, and that they had the right to withdraw from the study without penalty and without needing to give a reason. Should a participant request to withdraw from the study, he/she would be allocated to a nonparticipating tutorial group, arranged by the faculty's administrative coordinator.

Two sets of measurements were carried out throughout the nine-week course. Each set of measurement revolved around one PBL topic (structure shown in Fig. 5). The first set started on April 10, 2018, and the second set started on May 8, 2018 (see Table 2).

\subsection{Data management}

The audio recordings will be transcribed verbatim; information containing individual identities will be removed. The audio recordings will be stored according to the requirements of data protection legislation. After transcription, the audio recordings will be destroyed to protect the students' and tutors' privacy. The students and tutors will be given the opportunity to review their group's transcripts to verify their accuracy and withdraw any content that they deem inappropriate for the public domain. All data collected 
Table 2

Schedule across April - June 2018.

\begin{tabular}{|c|c|c|c|c|}
\hline Monday & Tuesday & Wednesday & Thursday & Friday \\
\hline April 9 & $\begin{array}{l}\text { April } 10 \\
\text { Set 1: Session } 1\end{array}$ & April 11 & April 12 & April 13 \\
\hline April 16 & $\begin{array}{l}\text { April } 17 \\
\text { Set 1: Session } 2 \\
\text { (pre-discussion) }\end{array}$ & April 18 & April 19 & $\begin{array}{l}\text { April } 20 \\
\text { Set 1: Session } 3 \\
\text { (post-discussion) }\end{array}$ \\
\hline April 23 & April 24 & April 25 & April 26 & April 27 \\
\hline April 30 & $\begin{array}{l}\text { May } 1 \\
\text { Set 1: Activity } \\
\text { Monitoring }\end{array}$ & May 2 & May 3 & $\begin{array}{l}\text { May } 4 \\
\text { Set 1: Session } 4\end{array}$ \\
\hline May 7 & $\begin{array}{l}\text { May } 8 \\
\text { Set 2: Session } 1\end{array}$ & May 9 & May 10 & May 11 \\
\hline May 14 & $\begin{array}{l}\text { May } 15 \\
\text { Set 2: Session } 2 \\
\text { (pre-discussion) }\end{array}$ & May 16 & May 17 & $\begin{array}{l}\text { May } 18 \\
\text { Set 2: Session } 3 \\
\text { (post-discussion) }\end{array}$ \\
\hline May 21 & May 22 & May 23 & May24 & May 25 \\
\hline May 28 & May 29 & May 30 & May 31 & $\begin{array}{l}1 \text { June } 1 \\
\text { Set 2: Session } 4 \\
\text { and Activity } \\
\text { Monitoring }\end{array}$ \\
\hline June 4 & June 5 & June 6 & June 7 & June 8 \\
\hline
\end{tabular}

Note. Grayed out dates do not have tutorial classes scheduled.

on paper will be scanned and saved electronically. Both electronic and paper data will be stored securely and only the primary researcher will have access (via password and key) to the data. The researcher will encrypt all personal information with a code, to which only she will have the key. The encrypted data will be stored separately from the main study data. After the data collection phase, all data will be anonymized completely.

All collected data will be kept in a secure storage for a period of 15 years after the completion of this study, as mentioned in the students' informed consent form. As this study was non-invasive, with a consenting, non-blinded adult population, no data monitoring committee will be set up. Furthermore, the students' gatekeepers, i.e., the course coordinator and tutors, were present to ensure that the students' wellbeing and privacy were always prioritized.

Upon completion of data analysis, the results of this exploratory RCT will be further disseminated to the public through academic publications and presentations at conferences.

\subsection{Analysis}

The analysis and reporting of the results of this study will follow the Consolidated Standards for Reporting Trials (CONSORT) 2010 checklist for randomized trials (Schulz, Altman, Moher, \& Group, 2010).

\subsubsection{Thematic analysis of audio recordings/tutorial discussions}

Visschers-Pleijers, Dolmans, de Leng, Wolfhagen, and van der Vleuten, 2006; 2005) identified three types of learning-oriented interactions within PBL tutorials (adopted from Mercer, 1995 model). The first one is exploratory questioning, consisting of open questions, critical questions, verification questions, and possible alternative arguments, which points to the critical and constructive engagement with ideas presented by group members. The second type of interaction is cumulative reasoning, referring to the construction of common understanding by building upon each other's knowledge. The third type would be handling conflicts about knowledge, which is the acknowledgement and discussion of disagreements. The use of these learning-oriented interactions signals that learning is occurring, in contrast to the other interaction types such as procedural or irrelevant interactions (Visschers-Pleijers 
et al., 2006). The coding scheme generated by Visschers-Pleijers et al. (2006) will be used to identify the types of interactions that had occurred in the tutorial groups.

As for dissecting the transcription into single units for coding, this study will refer to Visschers-Pleijers et al. (2006) definition of units of analysis: each unit of analysis is expressed by one student, dealing with one topic, with one communicative function (e.g., question, argument or evaluation). The length of each unit can vary from one word to several sentences. Three raters (HQC, PWMVG, and HHCMS) will independently code an hour's worth of tutorial discussion. Interrater agreement will be measured and reported. Should interrater agreement be high $(>75 \%)$, then the primary researcher will code the remaining transcriptions.

\subsubsection{Text analysis}

The usage of specific word categories represents the various psychological processes occurring within the tutorial discussions (Tausczik \& Pennebaker, 2010). For example, causal words and insight words point to the active process of reappraisal within the discussions. Differentiation and conjunction words show cognitive complexity within the discussions. A high number of analytic words indicate formal, logical, and hierarchical thinking, while a low number suggests a narrative style of thinking. The Linguistic Inquiry and Word Count 2015 (LIWC2015) program is a text analysis application developed to study the emotional, cognitive, and structural aspects of verbal speech (Pennebaker, Booth, Boyd, \& Francis, 2015; Pennebaker, Boyd, Jordan, \& Blackburn, 2015), with acceptable external (Kahn, Tobin, Massey, \& Anderson, 2007), convergent and divergent validity (Bantum \& Owen, 2009). Using this program, the frequency of different word categories used will be compared between tutorials.

The transcription produced from the tutorial audio-recordings will be analyzed word-by-word, processed to match words from LIWC2015 program's dictionary and categorized. The LIWC2015 produces 90 output variables for each transcription file, including word count, summary language variables (e.g., analytical thinking), linguistic dimensions (e.g., pronouns), psychological processes (e.g., affect), personal concerns (e.g., money), informal language (e.g., fillers), and punctuation categories (e.g., question marks) (Tausczik \& Pennebaker, 2010).

Following the LIWC2015 Operator's Manual (Pennebaker, Booth, Boyd, \& Francis, 2015), careful measures will be taken when transcribing the verbal exchanges. Nonfluency words, such as stutters, "err" and "uh-huh" will be transcribed to the standard forms that are part of the dictionary (e.g., "hm", "um", "uh", "no" and "yes"). Filler words, such as "you know", "I mean", "I don't know", "like" and "well", will be transcribed to "youknow", "imean", "idontknow", "rrlike" and "rrwell" to indicate that these are filler words, and do not employ their literal meanings. Transcribers" remarks such as [laughter] and [inaudible] will be removed from the transcription before being processed with the LIWC2015.

\subsubsection{Concept tests}

The keywords produced at each concept test will be given a score ranging from 0 to 3 , with 0 being not relevant or important to the topic, to 3 being very relevant or important to the topic. The relationships between the keywords in the concept map will be given a correct or incorrect score. Two expert raters will be brought in to carry out the scoring independently. Interrater agreement will be measured and reported. The total score will be counted to give an estimation of the students' learning.

\subsubsection{Activity monitoring}

The activity data recorded on the activPAL will be downloaded using the PAL Software (Version 7.2.38). The generated data (.PAL) file will be processed in MATLAB (Mathworks, Inc.) using the Maastricht Study's activPAL algorithm to identify waking time and sleeping time in order to give a more valid measure of the various activity levels (van der Berg et al., 2016). This sleep-wake algorithm imposes certain requirements to identify non-valid days when participant error (e.g., not attaching or removing the activPAL) is suspected. These requirements include: no change in posture for more than 12 hours, being sedentary for more than seven hours between $8: 00 \mathrm{~h}$ and 18:00 $\mathrm{h}$, or more than seven hours of dynamic or standing activity starting from 0:00 h to 06:00 h. The modified IPAQ will be used to verify non-valid days that are potentially identified by the sleep-wake algorithm.

\subsubsection{Statistical analyses}

Other than the primary measures of learning and activity monitoring, the data gathered from the students' final grades on the course, positive and negative affect, attendance, extent of studying, tutor's perception on group discussion, and tutor evaluation will be used to compare and test for significance between the sitting and standing tutorials and across time points. Due to the design of this study needing to compare the outcome measures between-subject across time, a mixed ANOVA will be used to analyze the data. Statistical analysis will be performed using the IBM SPSS Statistics for Windows (version 25.0, Armonk, NY, US).

\section{Discussion}

The aim of this exploratory RCT is to compare learning among undergraduate students between standing tutorial classes and the traditional sitting tutorial classes. Learning was measured, and will be analyzed, through the students' tutorial discussions, their performance on concept tests, and their final exam grades. A secondary aim to this study is to explore the unintended effects of introducing standing tutorials, observed through the students' subsequent physical activity, attendance and affect. The purpose of drawing up a protocol paper is to detail the rationale and steps taken within this mixed methods, exploratory and longitudinal RCT.

The strength of this study is that it is embedded within real tutorials. This study takes into account the instructional format employed within the institution, i.e., the PBL educational model in this case. PBL recognizes that learning starts with the students' preexisting cognitive schema, i.e., their prior knowledge. The students continue to update their schema while they learn, aligning 
with Bartlett's classical schema theory of learning (Bartlett, 1932). This study takes advantage of the social-constructive structure that PBL has built within Maastricht University's tutorials by measuring the students' prior knowledge and their subsequent schemas throughout their process of learning.

Another strength of this exploratory study is the use of method triangulation to measure learning: first, learning was measured with concept tests to detect the changes in the students' cognitive schema; second, exam grades were collected for comparison; and third, the tutorial discussions were audio recorded for analysis. Additionally, the tutors answered a questionnaire, giving their judgment on the learning-oriented interactions that occurred within their tutorial discussions. Learning will thus be analyzed through whether or not the discussions were conducive to learning, the underlying psychological processes during the discussions, and the length of the discussions carried out. Unlike previous studies, this study did not measure specific cognitive abilities that are assumed to be a proxy for learning. Instead, this study acknowledges the multifaceted nature of learning and attempts to study learning in depth.

One limitation within this study is that individual speakers will not be identified within the tutorial discussions. In a pilot study, the authors tested the usage of video recording to identify the speakers. However, the students reported feeling very uncomfortable with the video recording. Therefore, a small audio recorder was used in this study to encourage a more natural discussion setting. Nevertheless, PBL is a constructive learning model, where the students learn by building upon each other's discussions (Yew, Chng, \& Schmidt, 2011). Therefore, there is no need for individual speakers to be identified. However, the tutors' contributions to the discussion may have affected the quality and length of the discussion. To minimize the influence of the tutor on the results, the tutors each taught a sitting and a standing tutorial. Furthermore, the Tutor Evaluation Questionnaire serves as a measure of whether the tutor's performance potentially impacted the tutorial discussions.

As the current study utilized a field setting, where real tutorials are kept as naturalistic as possible, individual differences were not explored and assumed to be minimized through the randomized-controlled design of this study. However, it is recommended for future studies to explore the influence of individual differences among students, for example students' fitness levels, activity levels, and arousal levels (including sleep duration and quality, caffeine and alcohol consumption, and so on), and how these may moderate or mediate the effects of standing during learning.

Nonetheless, this exploratory study has several practical implications. First, it carves out a clearer pathway, to inform the design of future definitive RCTs. Second, should these studies find that learning while standing improves learning performance, then educational institutions and policies will be recommended to introduce standing desks within classrooms. If the studies find that standing is no different than sitting, then adjustable standing desks will still be recommended to counteract the health risks of excessive SB. However, should detrimental effects be found from standing education, then educators and policy makers will be asked to weigh the physical health benefits of introducing standing desks against the importance of learning within educational institutions.

\section{Consent for publication}

Consent for publishing the protocol and results of this study has been given by the course coordinator, tutors and students involved.

\section{Availability of data and materials}

Data generated from this study will be available on reasonable request via the corresponding author.

\section{Author's contributions}

HQC is the primary researcher, responsible for study design, collection, management, analysis, and writing of the report. HQC and RHJE tested the experimental design before applying it in this study. PWMVG, RHMDG, MGAOE, RHJE and HHCMS are responsible for supervising, guiding, advising, and assisting HQC in carrying out the study. As a team, all authors are responsible for the decision to submit the report for publication.

\section{Funding}

This research did not receive any specific grant from funding agencies in the public, commercial, or not-for-profit sectors.

\section{Protocol amendment number}

01 (Original).

\section{Declaration of Competing Interest}

None. 


\section{Acknowledgements}

The authors would like to thank the BIO2005 Evolutionary Biology class (2017-2018) of the Maastricht Science Programme for participating in the pilot and helping to optimize the design of this study.

The authors would like to express their gratitude towards the students, tutors and course coordinator (including the expert scorers) for participating and contributing to this study.

The authors are grateful for the help given by the voluntary research assistants: Amber van Dulmen, Chantal Witsiers, Farah Alkhotany, Kato Herman, and Marius Smits.

The authors are thankful for the adjustable, electronic standing desks provided by EDLAB (Maastricht University's institute for education innovation).

The authors are appreciative of the assistance provided by the administrative staff of the department of Educational Development and Research and the Institute for Education of the Faculty of Health, Medicine and Life Sciences at Maastricht University.

\section{References}

Aragonés, A., Begoña, E. M. M., Pilar, C. E., Gil Luciano, A., Inés, Z. S., Terol Claramont, M., ... Barba Muñiz, M. (2015). Actividad física para la salud y reducción del sedentarismo. Recomendaciones para la población. Estrategia de Promoción de la Salud y Prevención en el SNS. Retrieved fromhttp://www.aecosan.msssi.gob.es/ AECOSAN/docs/documentos/nutricion/observatorio/Recomendaciones_ActivFisica_para_la_Salud.pdf.

Arain, M., Haque, M., Johal, L., Mathur, P., Nel, W., Rais, A., ... Sharma, S. (2013). Maturation of the adolescent brain. Neuropsychiatric Disease and Treatment, 9, 449-460. https://doi.org/10.2147/Ndt.S39776.

Atkin, A. J., Gorely, T., Clemes, S. A., Yates, T., Edwardson, C., Brage, S., ... Biddle, S. J. H. (2012). Methods of measurement in epidemiology: Sedentary behaviour. International Journal of Epidemiology, 41(5), 1460-1471. https://doi.org/10.1093/ije/dys118.

Australian Government - Department of Health (2014). Make your move - sit less. Become active for life! Australia's physical activity and sedentary behavior guidlines: Adults. Retrieved fromhttps://www.health.gov.au/internet/main/publishing.nsf/content/F01F92328EDADA5BCA257BF0001E720D/\$File/brochure\%20PA\% 20Guidelines_A5_13-17yrs.PDF.

Ball, K., Brown, W., \& Crawford, D. (2002). Who does not gain weight? Prevalence and predictors of weight maintenance in young women. International Journal of Obesity, 26(12), 1570-1578. https://doi.org/10.1038/sj.ijo.0802150.

Bantum, E. O., \& Owen, J. E. (2009). Evaluating the validity of computerized content analysis programs for identification of emotional expression in cancer narratives. Psychological Assessment, 21(1), 79-88. https://doi.org/10.1037/a0014643.

Bartlett, F. C. (1932). Remembering: A study in experimental and social psychology. Cambridge: CUP.

Boone, J. E., Gordon-Larsen, P., Adair, L. S., \& Popkin, B. M. (2007). Screen time and physical activity during adolescence: Longitudinal effects on obesity in young adulthood. The International Journal of Behavioral Nutrition and Physical Activity, 4. https://doi.org/10.1186/1479-5868-26.

Bouhuijs, P. A. J., \& Gijselaers, W. H. (1993). Course construction in problem-based learning. In P. A. J. Bouhuijs, H. G. Schmidt, \& H. J. M.v. Berkel (Eds.). Problembased learning as an educational strategy (pp. 79-90). Maastricht: Network of Community-Oriented Educational Institutions for Health Sciences.

Brown, W. J., Williams, L., Ford, J. H., Ball, K., \& Dobson, A. J. (2005). Identifying the energy gap: Magnitude and determinants of 5-year weight gain in midage women. Obesity Research, 13(8), 1431-1441. https://doi.org/10.1038/oby.2005.173.

Bundesamt für Sport BASPO (2013). Gesundheitswirksame Bewegung bei Kindern und Jugendlichen Empfehlungen für die Schweiz. Retrieved fromhttps://www.hepa.ch/de/ dokumentation.detail.document.html/hepa-internet/de/documents/bewegungsempfehlungen/hepa_Merkblatt_Gesundheitswirksame_Bewegung_Kinder_DE.pdf. html.

Chang, Y. K., Labban, J. D., Gapin, J. I., \& Etnier, J. L. (2012). The effects of acute exercise on cognitive performance: A meta-analysis. Brain Research, 1453, 87-101. https://doi.org/10.1016/j.brainres.2012.02.068.

Ching, P. L. Y. H., Willett, W. C., Rimm, E. B., Colditz, G. A., Gortmaker, S. L., \& Stampfer, M. J. (1996). Activity level and risk of overweight in male health professionals. American Journal of Public Health, 86(1), 25-30. https://doi.org/10.2105/Ajph.86.1.25.

Coakley, E. H., Rimm, E. B., Colditz, G., Kawachi, I., \& Willett, W. (1998). Predictors of weight change in men: Results from the health professionals follow-up study. International Journal of Obesity, 22(2), 89-96. https://doi.org/10.1038/sj.ijo.0800549.

Craig, C. L., Marshall, A. L., Sjostrom, M., Bauman, A. E., Booth, M. L., Ainsworth, B. E., ... Oja, P. (2003). International physical activity questionnaire: 12-country reliability and validity. Medicine and Science in Sports and Exercise, 35(8), 1381-1395. https://doi.org/10.1249/01.Mss.0000078924.61453.Fb.

Department of Health (2011). Start active, stay active: A report on physical activity for health from the four home countries' Chief Medical OfficersRetrieved fromhttp:// www.paha.org.uk/Resource/start-active-stay-active-a-report-on-physical-activity-from-the-four-home-countries-chief-medical-officers.

Dolmans, D. H. J. M., \& Ginns, P. (2005). A short questionnaire to evaluate the effectiveness of tutors in PBL: Validity and reliability. Medical Teacher, 27(6), 534-538. https://doi.org/10.1080/01421590500136477.

Dunstan, D. W., Barr, E. L. M., Healy, G. N., Salmon, J., Shaw, J. E., Balkau, B., ... Owen, N. (2010). Television viewing time and mortality the australian diabetes, obesity and lifestyle study (AusDiab). Circulation, 121(3), 384-391. https://doi.org/10.1161/Circulationaha.109.894824.

Edwardson, C. L., Winkler, E. A. H., Bodicoat, D. H., Yates, T., Davies, M. J., Dunstan, D. W., ... Healy, G. N. (2017). Considerations when using the activPAL monitor in field-based research with adult populations. Journal of Sport and Health Science, 6(2), 162-178. https://doi.org/10.1016/j.jshs.2016.02.002.

Faul, F., Erdfelder, E., Lang, A. G., \& Buchner, A. (2007). G*Power 3: A flexible statistical power analysis program for the social, behavioral, and biomedical sciences. Behavior Research Methods, 39(2), 175-191. https://doi.org/10.3758/Bf03193146.

Flemish Institute for Health Promotion and Disease Prevention (2015). Lang stilzitten: de' uitdaging van de 21ste eeuw. Factsheet sedentair gedrag. Retrieved fromhttps:// kics.sport.vlaanderen/Fitheidgezondheid/Documents/150921_VIGeZ_factsheetsedentairgedrag.pdf.

Fuster, J. M. (2002). Frontal lobe and cognitive development. Journal of Neurocytology, 31(3-5), 373-385. https://doi.org/10.1023/A:1024190429920.

Gijbels, D., Dochy, F., Van den Bossche, P., \& Segers, M. (2005). Effects of problem-based learning: A meta-analysis from the angle of assessment. Review of Educational Research, 75(1), 27-61. https://doi.org/10.3102/00346543075001027.

Health Promotion Board (2011). National physical activity guidelines: Professional guide. Retrieved fromhttps://www.ntu.edu.sg/has/SnR/Documents/NPAG_ Professional_Guide.pdf.

Hinckson, E., Salmon, J., Benden, M., Clemes, S. A., Sudholz, B., Barber, S. E., ... Ridgers, N. D. (2015). Standing classrooms: Research and lessons learned from around the world. Sports Medicine, 46(7), 977-987. https://doi.org/10.1007/s40279-015-0436-2.

Hmelo-Silver, C. E. (2004). Problem-Based Learning: What and How Do Students Learn? Educational Psychology Review, 16(3), 235-266. https://doi.org/10.1023/ B:EDPR.0000034022.16470.f3.

Hu, F. B., Li, T. Y., Colditz, G. A., Willett, W. C., \& Manson, J. E. (2003). Television watching and other sedentary behaviors in relation to risk of obesity and type 2 diabetes mellitus in women. Jama-Journal of the American Medical Association, 289(14), 1785-1791. https://doi.org/10.1001/jama.289.14.1785.

Kahn, J. H., Tobin, R. M., Massey, A. E., \& Anderson, J. A. (2007). Measuring emotional expression with the linguistic inquiry and word count. The American Journal of Psychology, 120(2), 263-286. https://doi.org/10.2307/20445398.

Katzmarzyk, P. T., Church, T. S., Craig, C. L., \& Bouchard, C. (2009). Sitting time and mortality from all causes, cardiovascular disease, and cancer. Medicine and Science in Sports and Exercise, 41(5), 998-1005. https://doi.org/10.1249/MSS.0b013e3181930355.

Knight, A. P., \& Baer, M. (2014). Get up, stand up: The effects of a non-sedentary workspace on information elaboration and group performance. Social Psychological 
and Personality Science, 5(8), 910-917. https://doi.org/10.1177/1948550614538463.

Kringen, N. L., Healy, G. N., Winkler, E. A. H., \& Clark, B. K. (2016). Accuracy of activPAL self-attachment methods. Measurement in Physical Education and Exercise Science, 20(3), 159-166. https://doi.org/10.1080/1091367x.2016.1189916.

Lajoie, Y., Teasdale, N., Bard, C., \& Fleury, M. (1993). Attentional demands for static and dynamic equilibrium. Experimental Brain Research, 97(1), $139-144$.

Landhuis, C. E., Poulton, R., Welch, D., \& Hancox, R. J. (2008). Programming obesity and poor fitness: The long-term impact of childhood television. Obesity, 16(6), 1457-1459. https://doi.org/10.1038/oby.2008.205.

Loyen, A., van der Ploeg, H. P., Bauman, A., Brug, J., \& Lakerveld, J. (2016). European sitting championship: Prevalence and correlates of self-reported sitting time in the 28 European Union Member States. PLoS One, 11(3), https://doi.org/10.1371/journal.pone.0149320 e0149320.

Maastricht University (2019). Problem-based learning. Retrieved fromhttps://www.maastrichtuniversity.nl/education/why-um/problem-based-learning.

Manson, J. E., Greenland, P., LaCroix, A. Z., Stefanick, M. L., Mouton, C. P., Oberman, A., ... Siscovick, D. S. (2002). Walking compared with vigorous exercise for the prevention of cardiovascular events in women. The New England Journal of Medicine, 347(10), 716-725. https://doi.org/10.1056/NEJMoa021067.

Matthews, C. E., Chen, K. Y., Freedson, P. S., Buchowski, M. S., Beech, B. M., Pate, R. R., ... Troiano, R. P. (2008). Amount of time spent in sedentary behaviors in the united states, 2003-2004. American Journal of Epidemiology, 167(7), 875-881. https://doi.org/10.1093/aje/kwm390.

Mehta, R. K., Shortz, A. E., \& Benden, M. E. (2016). Standing up for learning: A pilot investigation on the neurocognitive benefits of stand-biased school desks. International Journal of Environmental Research and Public Health, 13(1), https://doi.org/10.3390/ijerph13010059.

Mekary, R. A., Feskanich, D., Malspeis, S., Hu, F. B., Willett, W. C., \& Field, A. E. (2009). Physical activity patterns and prevention of weight gain in premenopausal women. International Journal of Obesity, 33(9), 1039-1047. https://doi.org/10.1038/ijo.2009.127.

Mercer, N. (1995). The guided construction of knowledge: Talk amongst teachers and learners. Clevedon, Avon, England: Multilingual Matters.

Meyer, A. M., Evenson, K. R., Couper, D. J., Stevens, J., Pereria, M. A., \& Heiss, G. (2008). Television, physical activity, diet, and body weight status: the ARIC cohort. The International Journal of Behavioral Nutrition and Physical Activity, 5. https://doi.org/10.1186/1479-5868-5-68.

Minges, K. E., Chao, A. M., Irwin, M. L., Owen, N., Park, C., Whittemore, R., ... Salmon, J. (2016). Classroom standing desks and sedentary behavior: A systematic review. Pediatrics, 137(2), https://doi.org/10.1542/peds.2015-3087 e20153087.

Ministry of Health (2015). Eating and activity guidelines for New Zealand adults. Retrieved fromhttps://www.health.govt.nz/publication/eating-and-activity-guidelinesnew-zealand-adults.

Nordic Council of Ministers (2012). Nordic nutrition recommendations 2012: Integrating nutrition and physical activity. Retrieved fromhttps://norden.diva-portal.org/ smash/get/diva2:704251/FULLTEXT01.pdf.

Oken, E., Taveras, E. M., Popoola, F. A., Rich-Edwards, J. W., \& Gillman, M. W. (2007). Television, walking, and diet - Associations with postpartum weight retention. American Journal of Preventive Medicine, 32(4), 305-311. https://doi.org/10.1016/j.amepre-2006.11.012.

PAL Technologies Ltd (2010). In PAL Technologies Ltd (Ed.). ActivPAL3 ${ }^{\text {TM }}$ operating Guide (PALaP3manual.2031.40525.1.3.docx). Glasgow, United Kingdom: PAL Technologies Ltd.

Pal Technologies Ltd (2018). Pal technologies - providing the evidence. Retrieved fromhttp://www.palt.com/.

Patel, A. V., Bernstein, L., Deka, A., Feigelson, H. S., Campbell, P. T., Gapstur, S. M., ... Thun, M. J. (2010). Leisure time spent sitting in relation to total mortality in a prospective cohort of US adults. American Journal of Epidemiology, 172(4), 419-429. https://doi.org/10.1093/aje/kwq155.

Pennebaker, J. W., Booth, R. J., Boyd, R. K., \& Francis, M. E. (2015). LIWC2015 operator's manual.

Pennebaker, J. W., Booth, R. J., Boyd, R. L., \& Francis, M. E. (2015). Linguistic inquiry and word count: LIWC2015. Retrieved fromhttp://liwc.wpengine.com/.

Pennebaker, J. W., Boyd, R. L., Jordan, K., \& Blackburn, K. (2015). The development and psychometric properties of LIWC2015.

Raynor, D. A., Phelan, S., Hill, J. O., \& Wing, R. R. (2006). Television viewing and long-term weight maintenance: Results from the national weight control registry. Obesity, 14(10), 1816-1824. https://doi.org/10.1038/oby.2006.209.

Ruetten, A., \& Pfeifer, K. (2016). Nationale Empfehlungen für Bewegung und Bewegungsförderung. Retrieved fromhttps://www.in-form.de/fileadmin/redaktion/Profi/ Aktuelles/Nationale-Empfehlungen-fuer-Bewegung-und-Bewegungsfoerderung-2016.pdf.

Sanchez-Villegas, A., Ara, I., Guillen-Grima, F., Bes-Rastrollo, M., Varo-Cenarruzabeitia, J. J., \& Martinez-Gonzalez, M. A. (2008). Physical activity, sedentary index, and mental disorders in the SUN Cohort Study. Medicine and Science in Sports and Exercise, 40(5), 827-834. https://doi.org/10.1249/MSS.0b013e31816348b9.

Schulz, K. F., Altman, D. G., Moher, D., \& Group, C. (2010). CONSORT 2010 Statement: Updated guidelines for reporting parallel group randomised trials. BMJ, 340, c332. https://doi.org/10.1136/bmj.c332.

Stamatakis, E., Hamer, M., \& Dunstan, D. W. (2011). Screen-based entertainment time, all-cause mortality, and cardiovascular events population-based study with ongoing mortality and hospital events follow-up. Journal of the American College of Cardiology, 57(3), 292-299. https://doi.org/10.1016/j.jacc.2010.05.065.

Tausczik, Y. R., \& Pennebaker, J. W. (2010). The psychological meaning of words: LIWC and computerized text analysis methods. Journal of Language and Social Psychology, 29(1), 24-54. https://doi.org/10.1177/0261927x09351676.

Titze, S. R.-D. S., Schober, P. H., Halbwachs, C., Samitz, G., Miko, H. C., Lercher, P., ... Arbeitsgruppe Körperliche Aktivitat/Bewegung/Sport der Osterreichischen Gesellschaft für Public Health (2012). O"sterreichische Empfehlungen für gesundheitswirksame Bewegung. Retrieved fromhttps://www.bmgf.gv.at/cms/home/ attachments/1/6/5/CH1357/CMS1405438552027/oe_empfehlung_gesundheitswirksamebewegung.pdf.

Tremblay, M. S., Aubert, S., Barnes, J. D., Saunders, T. J., Carson, V., Latimer-Cheung, A. E., ... Participants, S. T. C. P. (2017). Sedentary Behavior Research Network (SBRN) - terminology consensus project process and outcome. The International Journal of Behavioral Nutrition and Physical Activity, 14(75), https://doi.org/10. 1186/s12966-017-0525-8.

van den Hurk, M. M., Dolmans, D. H. J. M., Wolfhagen, I. H. A. P., Muijtjens, A. M. M., \& van der Vleuten, C. P. M. (1999). Impact of individual study on tutorial group discussion. Teaching and Learning in Medicine, 11(4), 196-201. https://doi.org/10.1207/S15328015tlm110403.

van der Berg, J. D., Willems, P. J., van der Velde, J. H., Savelberg, H. H., Schaper, N. C., Schram, M. T., ... Koster, A. (2016). Identifying waking time in 24-h accelerometry data in adults using an automated algorithm. Journal of Sports Sciences, 34(19), 1867-1873. https://doi.org/10.1080/02640414.2016.1140908.

Van Dijk, M. L., De Groot, R. H., Savelberg, H. H., Van Acker, F., \& Kirschner, P. A. (2014). The association between objectively measured physical activity and academic achievement in Dutch adolescents: Findings from the GOALS study. Journal of Sport \& Exercise Psychology, 36(5), 460-473. https://doi.org/10.1123/ jsep.2014-0014.

Visschers-Pleijers, A. J., Dolmans, D. H., de Leng, B. A., Wolfhagen, I. H., \& van der Vleuten, C. P. (2006). Analysis of verbal interactions in tutorial groups: A process study. Medical Education, 40, 129-137. https://doi.org/10.1111/j.1365-2929.2005.02368.x.

Visschers-Pleijers, A. J., Dolmans, D. H., Wolfhagen, I. H., \& van der Vleuten, C. P. (2005). Development and validation of a questionnaire to identify learning-oriented group interactions in PBL. Medical Teacher, 27(4), 375-381. https://doi.org/10.1080/01421590500046395.

Vuillerme, N., Isableu, B., \& Nougier, V. (2006). Attentional demands associated with the use of a light fingertip touch for postural control during quiet standing. Experimental Brain Research, 169(2), 232-236. https://doi.org/10.1007/s00221-005-0142-7.

Warren, T. Y., Barry, V., Hooker, S. P., Sui, X. M., Church, T. S., \& Blair, S. N. (2010). Sedentary behaviors increase risk of cardiovascular disease mortality in men. Medicine and Science in Sports and Exercise, 42(5), 879-885. https://doi.org/10.1249/MSS.0b013e3181c3aa7e.

Watson, D., Clark, L. A., \& Tellegen, A. (1988). Development and validation of brief measures of positive and negative affect - the panas scales. Journal of Personality and Social Psychology, 54(6), 1063-1070. https://doi.org/10.1037//0022-3514.54.6.1063.

Wijndaele, K., Brage, S., Besson, H., Khaw, K. T., Sharp, S. J., Luben, R., ... Ekelund, U. (2011). Television viewing time independently predicts all-cause and cardiovascular mortality: The EPIC Norfolk Study. International Journal of Epidemiology, 40(1), 150-159. https://doi.org/10.1093/ije/dyq105.

World Health Organization, \& Regional Office for the Western Pacific (2018). Pacific physical activity guidelines for adults: Framework for accelerating the communication of physical activity guidelines. Retrieved fromhttp://iris.wpro.who.int/handle/10665.1/5455.

Yew, E. H. J., Chng, E., \& Schmidt, H. G. (2011). Is Learning in Problem-Based Learning Cumulative? Advances in Health Sciences Education, 16, 449-464. https://doi. org/10.1007/s10459-010-9267-y. 